\title{
LAPATINIB IN BREAST CANCER - THE PREDICTIVE SIGNIFICANCE OF HER1 (EGFR), HER2, PTEN AND PIK3CA GENES AND LAPATINIB PLASMA LEVEL ASSESSMENT
}

\author{
Katerina Bouchalova ${ }^{\mathrm{a} * \#}$, Magdalena Cizkova ${ }^{\mathrm{a}, \mathrm{b} \#}$, Karel Cwiertka ${ }^{\mathrm{b}}$, Radek Trojanec ${ }^{\mathrm{a}}$, \\ David Friedeckyc, Marian Hajduch ${ }^{\mathrm{a}}$
}

\begin{abstract}
a Laboratory of Experimental Medicine, Institute of Molecular and Translational Medicine, Faculty of Medicine and Dentistry, Palacky University Olomouc and University Hospital Olomouc, Czech Republic

${ }^{b}$ Department of Oncology, Faculty of Medicine and Dentistry, Palacky University Olomouc and University Hospital Olomouc

c Laboratory for Inherited Metabolic Disorders, Institute of Molecular and Translational Medicine, Faculty of Medicine and Dentistry, Palacky University Olomouc and University Hospital Olomouc

\# Authors contributed equally to the work

E-mail: bouchalova@seznam.cz
\end{abstract}

Received: October 18, 2010; Accepted: December 14, 2010

Key words: Lapatinib/HER1(EGFR, ErbB1)/HER2(ErbB2, Neu)/PTEN/PIK3CA/Dual tyrosine kinase inhibitor/Targeted therapy/Biological therapy/Metastatic breast cancer/Lapatinib plasma level

Background. Breast cancer treatment trends are currently based on tailored therapies using tumor and patient biomarkers. Lapatinib is the first dual inhibitor of HER1 (EGFR, ErbB1) and HER2 (ErbB2, Neu) tyrosine kinases to be used in clinical practice. However, only HER2 is currently used for therapy indications and new predictors for the treatment with lapatinib are sought.

Methods and results. This minireview focuses on lapatinib and its role in breast cancer treatment. Preclinical and clinical studies as well as pharmacological characteristics are briefly reviewed while the focus is on efficacy assessment including predictive factors for therapy outcome.

Conclusion. Lapatinib (Tykerb/Tyverb) was Food and Drug Administration (FDA) approved in 2007 for use in combination with capecitabine for the treatment of HER2-positive advanced or metastatic breast cancer in patients who had received previous treatment (including anthracycline, taxane and trastuzumab containing regimens) and in 2010 for use in combination with letrozole for postmenopausal women with hormonal receptor positive and HER2positive metastatic breast cancer. In contrast to trastuzumab (Herceptin), lapatinib is orally administered and it targets both HER2 and HER1 receptors. As a synthetic and oral tyrosine kinase inhibitor (TKI), it is convenient, cheaper and easier to produce than monoclonal antibodies. The recommended dosage is not dependent on body weight either. Lapatinib plasma level measurement could be an approach to tailored therapy for further optimizing the dose and prolonging this efficient therapy. New lapatinib response predictors are being evaluated. At this time, only HER2 amplification/overexpression is used to choose lapatinib therapy candidates. Further studies on concurrent HER1 fluorescent in situ hybridization (FISH)/immunohistochemistry (IHC) assessment and/or microarray analyses may produce new data on the predictive role of the HER1 (EGFR) gene/protein. PTEN loss and PIK3CA gene mutations are other markers that may predict lapatinib poor response.

\section{INTRODUCTION}

Breast cancer (BC) is the most common malignancy in females affecting around 1.3 million women worldwide each year and causing about 460,000 deaths annually ${ }^{1,2}$. Data from the Czech National Oncology Registry ${ }^{3}$ indicate that the incidence of BC has doubled since 1977 and in 2007 BC affected 123.2/100,000 women with a mortality of 31.9/100,000 (ref. ${ }^{3,4}$ ). Metastatic breast cancer (MBC) is found at initial diagnosis in up to $10 \%$ of patients ${ }^{3,5,6}$. Tailored therapy based on biological markers of tumor and patient is the trend in clinical practice these days. Lapatinib (Tykerb/Tyverb, GlaxoSmithKline, Research Triangle Park, NC) was introduced into routine clinical settings and follows success of hormonal therapy (used in hormonal receptor positive BC) and the mono- clonal antibody trastuzumab (Herceptin, Genentech, South San Francisco, CA) indicated in HER2 overexpressed and/or amplified breast cancers ${ }^{7-10}$. This minireview focuses on lapatinib in BC treatment. Preclinical and clinical studies as well as pharmacological characteristics are briefly reviewed while the focus is on efficacy assessment including predictive factors for therapy outcome.

\section{THE HER FAMILY AND ITS BLOCKADE}

The family of cell receptors called human epidermal growth factor receptors (HER) plays an important role in tumor development via influence on cell proliferation, migration, angiogenesis and protection against apoptosis in many cancer types. The HER family consists of four 
members - HER1 (also known as epidermal growth factor receptor, EGFR), HER2, HER3 and HER4. These receptors are composed of an N-terminus extracellular ligand-binding domain, a single membrane spanning region and a $\mathrm{C}$-terminus cytoplasmic domain which exhibits tyrosine kinase activity. However, HER2 has no known ligand and HER3 lacks tyrosine kinase activity ${ }^{6,11,12}$. After ligand binding on extracellular domains, receptors homo- or heterodimerize and become active through autophosphorylation. This activation allows further signal transduction. The intracellular downstream signal is split into two important pathways: the mitogen-activated protein kinase (MAPK) and the phosphatidylinositol 3-kinase (PI3K)Akt pathways ${ }^{6,12}$.

Two main approaches are used in cancer therapy to block membrane receptors and thus their signaling - via monoclonal antibodies or blocking kinase activity using small molecules - TKIs. Monoclonal antibodies are intravenously administered. They bind the extracellular domain of the receptor, inhibit signaling and attract immune response. On the other hand, TKIs are orally administered small molecules targeting the intracellular part of the receptors. In the case of $\mathrm{BC}$, both approaches are used in clinical practice ${ }^{8,13-16}$. Both trastuzumab, and lapatinib, have been approved by the FDA and the European Medicines Agency (EMEA) for BC treatment. Lapatinib (Tykerb/Tyverb) was FDA approved in 2007 for use in combination with capecitabine for the treatment of HER2-positive (HER2+) advanced or MBC in patients who had received previous treatment (including anthracycline, taxane and trastuzumab containing regimens) and in 2010 it was approved in combination with letrozole for postmenopausal women with hormonal receptor positive and HER2+ $\mathrm{MBC}^{8,10,17-20}$.

TKIs are cheaper and easier to produce than monoclonal antibodies ${ }^{21}$. As they are taken orally this is a great advantage to cancer patients, $83-92 \%$ of whom prefer this form of administration according to various studies ${ }^{22-26}$.

\section{Lapatinib - mechanism of action}

Lapatinib (GW572016) was derived from the quinazoline core found to be active in other HER TKIs. Its chemical name is $\mathrm{N}$-\{3-chloro-4-[(3-fluorobenzyl)oxy]phenyl]-6-[5-(\{ [2-(methylsulfonyl)ethyl] amino ]methyl)2-furyl]-4-quinazolinamine ${ }^{27}$. It has been shown to inhibit the intracellular domain phosphorylation of both HER2 and HER 1 in a reversible manner with a long dissociation time of receptor-drug complex estimated as $\geq 300$ min. The described effect is due to the lapatinib structure and its ability to bind at an ATP binding site in inactive form ${ }^{6,28}$. In humans, lapatinib is administered as the monohydrate ditosylate salt ${ }^{6}$. The specificity of lapatinib has been tested on a wide range of protein kinases. An affinity was found only for HER4 and c-Src apart, that is from HER2 and HER $1^{18}$. Lapatinib blocks, by inhibition of HER2 and HER1, activation of subsequent intracellular pathways leading through extracellular signal-related kinase (ERK)-1/2 and PI3K/Akt ${ }^{29-31}$. Lapatinib can inhibit both wild-type and truncated forms of HER2 receptors (p95HER2) both in vitro and in vivo ${ }^{32,33}$.

\section{In vitro and xenograft studies}

Rusnak et al. ${ }^{29}$ showed growth inhibition of tumor cells overexpressing both receptors - HER1 (head and neck cancer, vulvar cancer cell lines) and HER2 (breast, gastric, lung cancer cell lines). The ability of lapatinib to inhibit the proliferation of tumor cells overexpressing HER1 was compared with erlotinib and a similar impact on growth was found. Inhibition of HER1 and HER2 receptor autophosphorylation and phosphorylation of the downstream modulator, Akt, was verified by Western blot in the BT474 and HN5 cell lines. HER1 and HER2 receptor autophosphorylations were similarly inhibited by lapatinib. However the level of Akt phosphorylation was, post-treatment, lower in HER2+ samples than in HER1 positive samples. In proliferation and cell cycle assays, lapatinib proved to be more effective against HER2-overexpressing cell lines than against HER1overexpressing cell lines. However these results might be due to the specific cell lines used. The results suggest that HER1 inhibition leads preferentially to cell growth arrest and HER2 inhibition causes both growth arrest and cell death after $72 \mathrm{~h}$ in vitro. The authors also confirmed that lapatinib was capable of inhibiting the growth of human tumor cells in vivo, using HN5 and BT474 xenograft models. Taken together, these results indicate that lapatinib achieves excellent potency on tumor cells with selectivity for tumor versus normal cells and they suggest that lapatinib would benefit patients with tumors overexpressing either HER1 or HER2. Another study showed potent inhibition of both HER1 and HER2 tyrosine kinases leading to growth arrest and/or apoptosis in HER1 and HER2-dependent tumor cell lines as a response to lapatinib treatment. Lapatinib markedly reduced tyrosine phosphorylation of both HER1 and HER2, and inhibited activation of Erk1/2 and Akt. However, the inhibition of phosphorylated ( $\mathrm{p}$ )-Akt in HN5 cells overexpressing HER1 was smaller than in HER2-overexpressing tumor cells. Lapatinib inhibited activation of HER1, HER2, Erk1/2 and Akt in human tumor xenografts as well ${ }^{34}$. Lapatinib efficacy both in vitro and in vivo was also confirmed by Konecny et $\mathrm{al}^{31}$.

\section{Clinical studies}

Phase I clinical studies have proven the safety of lapatinib administration either alone $e^{35,36}$ or in combination with another oral agent, capecitabine ${ }^{37,38}$. In the phase I study of Burris et al. ${ }^{36}$, out of 67 patients with advanced solid tumors displaying HER1 expression by immunohistochemistry (IHC) and/or HER2 overexpression by IHC or amplification by fluorescence in situ hybridization (FISH) 30 (44.7\%) were treated for BC. Patients who experienced complete remission, partial response (PR) or stable disease in the phase I studies were mainly those suffering from $\mathrm{BC}^{36,38}$. The phase II study in HER2+ MBC patients after trastuzumab treatment failure, produced more results supporting the safety of lapatinib and it evaluated its benefits ${ }^{39,40}$. Lapatinib demonstrated modest activity as a single agent ${ }^{40}$. A combination of capecitabine and lapatinib significantly prolonged treatment efficacy with acceptable toxicity ${ }^{19,41}$. The phase III clinical evalua- 
tion showed better response to lapatinib with capecitabine than capecitabine alone in a group of HER2 + BC patients suffering from locally advanced or metastatic disease ${ }^{41}$. Lapatinib also inhibited truncated forms of HER2 receptor (p95HER2) in BC patients, partially explaining its activity in trastuzumab resistant disease ${ }^{32,33}$. The development of CNS metastases is a serious clinical problem occurring in approximately one third of women with $\mathrm{MBC}$ who receive trastuzumab ${ }^{42,43}$. The phase II studies using lapatinib in $\mathrm{BC}$ with brain metastases showed volumetric changes in the metastases ${ }^{44}$. Lapatinib plus capecitabine resulted in 20\% CNS objective response and in $40 \%$ $a \geq 20 \%$ volumetric reduction in their CNS lesions was observed $^{45}$. More recently, other studies on lapatinib in combinations have been published: with trastuzumab ${ }^{46}$, paclitaxel $^{47}$ and hormonal treatment ${ }^{48,49}$, some also in neoadjuvant settings ${ }^{47}$. One study exploring the combination of anthracycline-based chemotherapy plus trastuzumab, lapatinib, or both in a neoadjuvant setting is ongoing ${ }^{50}$. Important and relevant outcomes are expected from an international ALTTO phase III adjuvant trial that will evaluate 8,000 early HER2+ BC patients and will produce data on lapatinib and trastuzumab in combination, both alone and in sequence. The first patient was enrolled in 2007. BC patients will receive study treatment for one year, and will be followed for a total of 10 years ${ }^{51}$. A companion trial will evaluate lapatinib in the neoadjuvant treatment of BC (Neo-ALTTO) ${ }^{51}$.

\section{Pharmacokinetics}

Absorption: Lapatinib is a small orally administered molecule, whose absorption depends on concurrent conditions. Detectible levels of lapatinib are found in the blood after 0.25 hours ranging from 0 to 1.5 hours with the maximum concentration reached approximately after 3 to 4 hours. A daily dose of $1,250 \mathrm{mg}$ causes steady state levels of Cmax $2.43 \mathrm{mcg} / \mathrm{ml}$ (1.57 to $3.77 \mathrm{mcg} / \mathrm{ml})$ and the area under the curve (AUC) $36.2 \mathrm{mcg} . \mathrm{hr} / \mathrm{ml}$ (23.4 to $56 \mathrm{mcg} . \mathrm{hr} / \mathrm{ml}$ ). With multiple daily dosing, a steady state

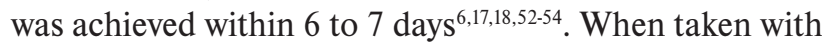
food, lapatinib absorption is increased ${ }^{52,53}$. In the case of high-fat food (characterized as $50 \%$ of fat and 1,000 calories) AUC values were approximately 4-fold higher ( $\mathrm{Cmax}$ approximately 3-fold higher) $)^{17,18,52-54}$. Lapatinib plasma levels were also higher when lapatinib was combined with capecitabine compared to lapatinib alone but the difference did not reach statistical significance ${ }^{38}$. Distribution: Lapatinib is bound (>99\%) to albumin and alpha-1 acid glycoprotein in the blood stream but it does not undergo erythrocyte binding which creates a blood to plasma ratio $<1$. In vitro studies have shown that lapatinib is a substrate for and inhibitor of P-glycoprotein (Pgp $)^{6}$. Metabolism and elimination: The metabolism depends primarily on CYP3A4 and CYP3A5, with minor contributions from CYP2C19 and CYP2C8 followed by biliary elimination and stool excretion. Renal excretion accounts for less than $2 \%$ of the given dose $e^{6,17,18}$. The elimination $t_{1 / 2}$ was 14.2 hours after a single dose administration, and 24 hours with repeated dosing (result of drug accumulation) $)^{6,17,18,52-54}$. In patients with severe hepatic dysfunction (Child-Pugh class
C), the AUC of lapatinib was increased by $>60 \%$ and the $\mathrm{t}_{1 / 2}$ was 3 times that of individuals without hepatic disorder. Thus, dose reductions to $750 \mathrm{mg} / \mathrm{d}$ are recommended in patients with liver disease. Ketoconazole, a CYP3A4 inhibitor, increases the AUC of lapatinib and $t_{1 / 2}$. The package insert recommends avoidance of strong CYP3A4 inhibitors. If co-administration is necessary, reduction of the lapatinib dose to $500 \mathrm{mg} / \mathrm{d}$ is advised. On the other hand, carbamazepine, a CYP3A4 inducer, decreases the AUC of lapatinib. Avoidance of strong CYP3A4 inducers is recommended, and if it is necessary to receive a strong CYP3A4 inducer in combination with lapatinib, the dose of lapatinib should be titrated gradually from $1,250 \mathrm{mg} /$ day up to $4,500 \mathrm{mg} /$ day (HER2 positive MBC indication) or from $1,500 \mathrm{mg} /$ day up to $5,500 \mathrm{mg} /$ day (hormone receptor positive, HER2+ $\mathrm{BC}$ indication) based on tolerability as recommended by the FDA ${ }^{6,17,55}$. However, there are no published clinical data with this dose adjustment in patients receiving strong CYP3A4 inducers.

\section{Resistance to lapatinib}

As a small tyrosine kinase molecule, lapatinib affects receptors and signal transduction at a different level than trastuzumab. Moreover, different modes of cellular drug resistance have been suggested for trastuzumab and lapatinib and this underlines the rationale of lapatinib administration after trastuzumab failure ${ }^{56}$. However, some BCs do not respond or develop resistance to lapatinib too (e.g. tumors with HER2 tyrosine kinase domain mutations; HER1 tyrosine kinase domain mutations; PIK3CA mutation, PTEN loss, AXL overexpression, RelA activation $)^{57-62}$. Enhanced estrogen signaling described in vitro may also be a route for increased tumor cell survival on lapatinib treatment. Combining lapatinib treatment with fulvestrant reduced the rate of lapatinib resistance ${ }^{63}$. One in vitro study has shown AXL overexpression as a novel mechanism of acquired resistance to HER2-targeted agents, which can be overcome by a new multikinase (AXL, MET, and VEGFR) inhibitor foretinib. Further, AXL expression in vitro was also decreased using small interfering RNA to AXL, estrogen deprivation or estrogen receptor antagonist fulvestrant and, sensitivity to lapatinib was restored ${ }^{60}$. These findings also suggest that epigenetic changes may play a role in lapatinib resistance ${ }^{60}$. Taken together, the results support the use of different targeted therapeutics in combination.

\section{Treatment tailoring and efficacy}

Response to lapatinib administration may be influenced both by tumor and patient characteristics. The tumor phenotype, predictor status, drug dose as well as other factors may play a role here. Lapatinib has been proven to be more absorbed by a high-fat $\operatorname{diet}^{52,54}$. The following steps of lapatinib body passage depend on liver metabolism and cytochrome inducers/inhibitors. The level of proteins in blood available to bind lapatinib plays another role by changing the free drug fraction ${ }^{17,18}$. Lapatinib insensitivity can also be caused by intratumoral signal pathway changes leading to an overwhelming of its inhibitory effect ${ }^{57-62}$. 


\section{THE HER FAMILY}

The HER1 gene is located on 7q12 and its protein product plays an important role in cell proliferation, migration and protection against apoptosis ${ }^{12}$. In contrast, to HER2, overexpression of HER1 appears to be a later event in tumorigenesis ${ }^{14}$. Increased HER1 protein expression is described in about $40 \%$ of BC, (ranging from $14 \%$ to $91 \%$ of all primary BC). High expression is described in triple negative breast cancer and metaplastic cancer (mostly basal-like $)^{7,14,6472}$. HER1 overexpression was found in $30 \%$ of inflammatory breast cancer (IBC). Patients with HER1-positive tumors have worse 5-year overall survival than patients with HER1-negative tumors, and HER 1 expression is associated with an increased risk of recurrence in patients with $\mathrm{IBC}^{73}$. The HER1 gene was amplified in a nonselected series in $0-14 \%$, in metaplastic cancer up to $28 \%$ (ref. ${ }^{7,14,64-69}$ ). In a study by Reis-Filho et al. ${ }^{69}$, which assessed 47 metaplastic cancers, HER1 amplification showed a significant association with HER1 overexpression and was restricted to cancers with homologous metaplasia. Coexpression of HER1 and HER2 has been observed in 10-36\% primary $\mathrm{BC}$, and it is associated with a poorer prognosis than in cases with expression of a single receptor ${ }^{74-77}$. In one study, where HER1 expression was found in only $15 \%$ of 807 invasive BC, the majority of HER1-positive tumors (87\%) coexpressed HER2. Moreover, almost all the tumors that expressed the HER2 phosphorylated form ( $\mathrm{pHER} 2$ ), coexpressed HER1, and expression of pHER2 or coexpression of HER2 and HER1 was associated with the shortest patient survival ${ }^{78}$. The HER2 gene is localized in the 17q12-q21 amplicon and its amplification occurs in approximately $20-35 \%$ of invasive $\mathrm{BC}^{79-84}$.

HER2 overexpression/amplification is widely accepted as a lapatinib therapy response predictor based on the results of several clinical studies ${ }^{15,85,86}$. Coexpression of pHER2 and pHER3 in IBC seems to predict a favorable response to lapatinib even more accurately ${ }^{87}$. On the other hand, HER1 did not predict lapatinib response in various studies ${ }^{15,40,85,88}$. However, HER1 protein was assessed using IHC but no HER1 gene examination by FISH was performed ${ }^{15,30,36,40,85,88}$. In another study, additional correlative tumor tissue analyses including HER1 were conducted, but the small number of responders precluded any useful interpretation of these results ${ }^{89}$. Further, the HER 1 status was not published in some studies ${ }^{38,44,45}$. In a phase I study of 67 patients with metastatic solid malignancies and using 6 different lapatinib doses ranging from 500 to $1,600 \mathrm{mg} / \mathrm{d}, 59$ patients were assessed for treatment results. Breast cancer presented in 15 out of 33 patients with assessed biomarkers. Four PR were observed: these were all in BC and all of them overexpressed HER2 at $3+$ level by IHC and three also displayed HER1 expression. HER 1 IHC results were described as positive or negative ${ }^{30,36}$. Detailed receptor status evaluation showed PR in patients with high HER2 activated level. Lapatinib treatment lowered both HER2 and HER1 phosphorylation but did not change overall receptor expression ${ }^{30}$. In a phase II study, HER2 overexpression but not HER1 expression alone, predicted sensitivity to lapatinib in IBC; high HER2, pHER2 and insulin-like growth factor receptor-1 (IGF-IR) coexpression predicted clinical response to lapatinib monotherapy in patients with relapsed/refractory IBC ${ }^{85}$. In a phase III study, investigators revealed the low frequency of HER1 IHC $2+$ or $3+$ overexpression $(44 / 320,14 \%$ in both arms, $25 / 163,15 \%$ in patients treated with lapatinib+capecitabine and in $19 / 157,12 \%$ treated with capecitabine) in the available tumor specimens. The results suggested that HER1 overexpression did not play a significant role in the biology of the HER2+ $\mathrm{BC}$ of women included in this trial. The authors were unable to identify a subgroup of patients who fail to benefit from the addition of lapatinib to capecitabine based on the biomarker studies. There was no association identified between level of HER1 expression and progression-free survival (PFS) $)^{15,41}$. Burstein et al. ${ }^{40}$ found no correlation between HER1 expression level assessed via IHC and response to lapatinib (six patients had an objective response to lapatinib by investigators review, two by independent review). Combined biomarker analysis was performed by Blackwell et al. ${ }^{90}$ in two large phase II studies with refractory $\mathrm{MBC}$ and they published initial data suggesting that expression levels of estrogen, progesterone and HER1 receptors may be related to lapatinib response in trastuzumab pretreated patients. Tumor tissues were obtained from each patient from the time of most recent biopsy. Phase II study EGF20009 assessed lapatinib as first line monotherapy in advanced or metastatic BC and for the initial 65 patient samples analyzed, an elevation of HER2 expression was significantly associated with response to treatment with lapatinib $(\mathrm{p}=0.02)$ and a longer time to progression following treatment with lapatinib $(p<0.0025)$. Further, of the $17 / 65$ responders in this preliminary study, SpotFire ${ }^{\mathrm{TM}}$ Decision Tree Analysis demonstrated that 16/17 (94\%) who responded to lapatinib had a gene expression signature combining HER1, 2, and 3 (ref. ${ }^{86}$ ). Further large studies focusing on concurrent HER1 FISH/IHC assessment or microarray analyses on samples from metastatic sites if available could produce new data on the predictive role of this marker. Comparison of HER1 gene/protein status in primary and metastatic sites may also be a tool to better assess the role of HER1 receptor in BC patients.

\section{PIK3CA}

Activation of the phosphoinositide 3-kinase (PI3K) pathway plays an important role in the pathogenesis of a variety of cancers. The gene encoding the p110alpha catalytic subunit of PI3K (PIK3CA) can be mutated in up to $40 \%$ of BC. The majority of PIK3CA mutations lie in two hotspot regions, including the central helical domain encoded by exon 9 and the $\mathrm{COOH}$-terminal kinase domain encoded by exon $20\left(\mathrm{ref}^{91}\right)$. The PIK3CA activating mutations (E545K and H1047R) cause resistance to lapatinib $^{58}$. Patients with tumors harboring an H1047R PIK3CA mutation or low expression of PTEN, derived clinical benefit from lapatinib in one phase II study ${ }^{92}$. 
On the other hand, PIK3CA mutations have recently been found to sensitize cancer cells (with KRAS/BRAF normal status) to the mammalian target of the rapamycin (mTOR) inhibitor everolimus ${ }^{61}$. Clinical trials testing mTOR inhibitors are currently ongoing, and this includes BC patients ${ }^{8,61,93}$. Taken together, PIK3CA mutations may serve as both positive (mTOR inhibition) and negative (lapatinib) therapy predictors in $\mathrm{BC}$.

\section{PTEN}

The phosphatase and tensin homolog deleted on chromosome 10 (PTEN) is a tumor suppressor identified in 1997 in the 10q23 region. PTEN phosphatase negatively regulates the PI3K pathway and is inactivated in many human malignancies, including $\mathrm{BC}^{91,94,95}$. However, there are no uniform study results. Knockdown of PTEN did not alter response to lapatinib in vitro and PTEN loss was not associated with reduced response to lapatinib in a phase II monotherapy trial in IBC, as approximately $70 \%$ of responders showed PTEN deficiency ${ }^{9,87,96}$. Patients with tumors harboring an H1047R PIK3CA mutation or low expression of PTEN derived clinical benefit from lapatinib in one phase II study ${ }^{92}$. On the other hand, a combined in vitro and in vivo study using a genome wide loss-of-function short hairpin RNA (shRNA) screen identified loss of PTEN expression as one of causes of lapatinib resistance $^{58}$. Recently, a distinct resistance mechanism has been proposed. PTEN inactivation specifically raised HER1 activity by impairing the ligand-induced ubiquitinylation and degradation of the activated receptor through destabilization of newly formed ubiquitin ligase $\mathrm{Cbl}$ complexes. This resistance can be overcome by more complete HER1 kinase inhibition ${ }^{97}$. PTEN deficient cells are also extremely sensitive to poly(ADP-ribose) polymerase (PARP) inhibitors and thus PARP inhibition is another hope for patients with PTEN deficiency ${ }^{98,99}$.

\section{LAPATINIB PLASMA LEVELS}

Effective plasma concentrations of lapatinib might be assessed using the approaches similar to common therapeutic drug monitoring. Such testing has already been suggested in the case of another TKI, imatinib which has been studied in relation to plasma concentration impact on treatment response in patients treated with the compound for chronic myeloid leukemia (CML) and gastrointestinal stromal tumors ${ }^{100-102}$. In the case of imatinib, higher plasma levels correlated with complete cytogenetic responses in CML patients. Plasma levels lower than those assessed as effective were significantly associated with worse treatment response ${ }^{102-105}$.

Imatinib plasma level evaluation supports the idea that a similar approach could be useful in lapatinib-treated patients. Lapatinib can be evaluated in patient blood samples. The recommended dose is not dependent on body weight. Lapatinib plasma level assessment could be a tool to identify patients in danger of treatment failure because of too low or too high lapatinib levels. Methods based on liquid chromatography and mass spectrometry have already been tested to determine lapatinib level in human plasma ${ }^{106,107}$. Haouala et al. ${ }^{107}$ described a method useful for a wide range of currently used TKIs including lapatinib and they suggest that free plasma levels should be assessed to obtain accurate estimates of drug quantity available to affect tumor cells. Nevertheless, lapatinib plasma levels have not been published in association with therapy outcome $38,106,107$. We applied a previously developed method for determination of imatinib in plasma for lapatinib, which is separated in 1.9 min under the same chromatographic conditions ${ }^{108-110}$ and we are currently evaluating the role of lapatinib plasma level assessment in therapy tailoring.

\section{CONCLUSION}

Lapatinib is a new therapeutic option for HER2+ BC patients. Interactions with other drugs metabolized by cytochromes P450 can influence lapatinib effectiveness, mainly with regard to CYP3A4 inhibitors and inducers. Resistance to lapatinib can be caused by genetic/epigenetic changes in tumor cells as well as by other factors leading to low and ineffective lapatinib concentrations in a tumor, e.g. reasons described in association with pharmacokinetics. At this time, only HER2 amplification/ overexpression is used to select the best lapatinib therapy candidates in routine clinical settings. Further studies focusing on HER1 (EGFR) gene/protein status assessment promise to provide new data on its predictive role. PTEN loss and PIK3CA gene mutations are markers that could also predict treatment response. Secondary resistance appearing during lapatinib treatment caused by tumor cell changes in DNA or protein expression is difficult to assess in patients on lapatinib treatment. Repeated tumor samples are needed for such an examination and these are not usually available in clinical practice. Thus markers quickly and easily available for assessment may play an important role in therapy tailoring. Pharmacokinetic influence on lapatinib efficacy might be easily assessed by lapatinib plasma levels representing changes in drug metabolism. Lapatinib plasma level assessment may also be a tool for identifying patients at risk of treatment failure or toxicity because of too low or too high lapatinib levels. A prospective clinical study evaluating such an approach would provide evidence of lapatinib plasma level assessment and its application in routine clinical practice with the aim of optimizing and prolonging this efficient therapy.

\section{ACKNOWLEDGEMENTS}

Supported by a grant of the Faculty of Medicine and Dentistry, Palacky University 91110301, Czech Ministry of Education MSM 6198959216, Czech Ministry of Healths IGA NS10286-3. Infrastructural part of this project (Institute of Molecular and Translational Medicine) was supported from the Operational Programme Research and Development for Innovations (project CZ.1.05/2.1.00/01.0030). 
The authors have no financial relationship(s) with commercial interests to disclose.

\section{REFERENCES}

1. http://globocan.iarc.fr/

2. Kloog I, Stevens RG, Haim A, Portnov BA. Nighttime light level codistributes with breast cancer incidence worldwide. Cancer Causes Control 2010. [Epub ahead of print]

3. www.svod.cz.

4. www.uzis.cz.

5. Lichter AS, Lippman ME, Danforth DN Jr, d'Angelo T, Steinberg SM, deMoss E, et al. Mastectomy versus breast-conserving therapy in the treatment of stage I and II carcinoma of the breast: a randomized trial at the National Cancer Institute. J Clin Oncol 1992;10:976-83.

6. Medina PJ, Goodin S. Lapatinib: a dual inhibitor of human epidermal growth factor receptor tyrosine kinases. Clin Ther 2008;30:1426-47.

7. Bouchalova K, Cizkova M, Cwiertka K, Trojanec R, Hajduch M. Triple negative breast cancer-current status and prospective targeted treatment based on HER1 (EGFR), TOP2A and C-MYC gene assessment. Biomed Pap Med Fac Univ Palacky Olomouc Czech Repub 2009;153:13-7.

8. Alvarez RH, Valero V, Hortobagyi GN. Emerging targeted therapies for breast cancer. J Clin Oncol 2010;28:3366-79.

9. Nahta R, Shabaya S, Ozbay T, Rowe DL. Personalizing HER2targeted therapy in metastatic breast cancer beyond HER2 status: what we have learned from clinical specimens. Curr Pharmacogenomics Person Med 2009;7:263-274.

10. Vogel C, Chan A, Gril B, Kim SB, Kurebayashi J, Liu L, et al. Management of ErbB2-positive Breast Cancer: Insights from Preclinical and Clinical Studies with Lapatinib. Jpn J Clin Oncol 2010. [Epub ahead of print]

11. Yarden Y, Sliwkowski MX. Untangling the ErbB signalling network. Nat Rev Mol Cell Biol 2001;2:127-137.

12. Hynes NE, Lane HA. ERBB receptors and cancer: the complexity of targeted inhibitors. Nat Rev Cancer 2005;5:341-54.

13. Gasparini G, Longo R, Torino F, Morabito A. Therapy of breast cancer with molecular targeting agents. Ann Oncol 2005;16 Suppl 4:iv28-36.

14. Hobday TJ, Perez EA. Molecularly targeted therapies for breast cancer. Cancer Control 2005;12:73-81.

15. Cameron D, Casey M, Press M, Lindquist D, Pienkowski T, Romieu $\mathrm{CG}$, et al. A phase III randomized comparison of lapatinib plus capecitabine versus capecitabine alone in women with advanced breast cancer that has progressed on trastuzumab: updated efficacy and biomarker analyses. Breast Cancer Res Treat 2008;112:533-43.

16. Rakha EA, Reis-Filho JS, Ellis IO. Combinatorial biomarker expression in breast cancer. Breast Cancer Res Treat 2010;120:293308.

17. www.fda.gov.

18. www.emea.europa.eu.

19. Capri G, Chang J, Chen SC, Conte P, Cwiertka K, Jerusalem G, et al. An open-label expanded access study of lapatinib and capecitabine in patients with HER2-overexpressing locally advanced or metastatic breast cancer. Ann Oncol 2010;21:474-80.

20. Steger GG, Abrahámová J, Bacanu F, Brincat S, Brize A, Cesas A, et al. Current standards in the treatment of metastatic breast cancer with focus on Lapatinib: a review by a Central European Consensus Panel. Wien Klin Wochenschr 2010;122:368-79.

21. Guirgis HM. A perspective on tyrosine kinase inhibitors in gastrointestinal stromal tumors and cancer: past and present with emphasis on future and cost. Case Study. Cancer Ther 2007;5:417-436.

22. Payne SA. A study of quality of life in cancer patients receiving palliative chemotherapy. Soc Sci Med 1992;35:1505-9.

23. Liu G, Franssen E, Fitch MI, Warner E. Patient preferences for oral versus intravenous palliative chemotherapy. J Clin Oncol 1997;15:110-5.
24. Topham C, Moore J. Patient preferences for chemotherapy schedules used in the treatment of advanced colorectal cancer-a pilot study. Eur J Cancer Care (Engl) 1997;6:291-4.

25. Borner MM, Schoffski P, de Wit R, Caponigro F, Comella G, Sulkes A, et al. Patient preference and pharmacokinetics of oral modulated UFT versus intravenous fluorouracil and leucovorin: a randomised crossover trial in advanced colorectal cancer. Eur J Cancer 2002;38:349-58.

26. Spurná Z, Brančíková D, Katolická J. Kvalita života pacienta při podávání perorální onkologické léčby. Onkologie 2009;3:101-105.

27. Petrov KG, Zhang YM, Carter M, Cockerill GS, Dickerson S, Gauthier CA, et al. Optimization and SAR for dual ErbB-1/ErbB-2 tyrosine kinase inhibition in the 6-furanylquinazoline series. Bioorg Med Chem Lett 2006;16:4686-91.

28. Bilancia D, Rosati G, Dinota A, Germano D, Romano R, Manzione L. Lapatinib in breast cancer. Ann Oncol 2007;18 Suppl 6:vi26-30.

29. Rusnak DW, Lackey K, Affleck K, Wood ER, Alligood KJ, Rhodes $\mathrm{N}$, et al. The effects of the novel, reversible epidermal growth factor receptor/ErbB-2 tyrosine kinase inhibitor, GW2016, on the growth of human normal and tumor-derived cell lines in vitro and in vivo. Mol Cancer Ther 2001;1:85-94.

30. Spector NL, Xia W, Burris H 3rd, Hurwitz H, Dees EC, Dowlati A, et al. Study of the biologic effects of lapatinib, a reversible inhibitor of ErbB1 and ErbB2 tyrosine kinases, on tumor growth and survival pathways in patients with advanced malignancies. J Clin Oncol 2005;23:2502-12.

31. Konecny GE, Pegram MD, Venkatesan N, Finn R, Yang G, Rahmeh M, et al. Activity of the dual kinase inhibitor lapatinib (GW572016) against HER-2-overexpressing and trastuzumabtreated breast cancer cells. Cancer Res 2006;66:1630-9.

32. Scaltriti M, Rojo F, Ocańa A, Anido J, Guzman M, Cortes J, et al. Expression of p95HER2, a truncated form of the HER2 receptor, and response to anti-HER 2 therapies in breast cancer. J Natl Cancer Inst 2007;99:628-38.

33. Scaltriti M, Chandarlapaty S, Prudkin L, Aura C, Jimenez J, Angelini PD, et al. Clinical benefit of lapatinib-based therapy in patients with human epidermal growth factor receptor 2-positive breast tumors coexpressing the truncated p95HER 2 receptor. Clin Cancer Res 2010;16:2688-95.

34. Xia W, Mullin RJ, Keith BR, Liu LH, Ma H, Rusnak DW, et al. Anti-tumor activity of GW572016: a dual tyrosine kinase inhibitor blocks EGF activation of EGFR/erbB2 and downstream Erk1/2 and AKT pathways. Oncogene 2002;21:6255-63.

35. Bence AK, Anderson EB, Halepota MA, Doukas MA, DeSimone PA, Davis GA, et al. Phase I pharmacokinetic studies evaluating single and multiple doses of oral GW572016, a dual EGFR-ErbB2 inhibitor, in healthy subjects. Invest New Drugs 2005;23:39-49.

36. Burris HA 3rd, Hurwitz HI, Dees EC, Dowlati A, Blackwell KL, O'Neil B, et al. Phase I safety, pharmacokinetics, and clinical activity study of lapatinib (GW572016), a reversible dual inhibitor of epidermal growth factor receptor tyrosine kinases, in heavily pretreated patients with metastatic carcinomas. J Clin Oncol 2005;23:5305-13.

37. De Bono JS, Schwarz G, Monroe P, Beeram M, Hammond L, Smith D, et al. Phase I and pharmacokinetic (PK) study of oral GW572016, a potent reversible dual inhibitor of both erbB1 and erbB2 tyrosine kinase (TK), administered in combination with capecitabine. ASCO, 39th Annual Meeting; 2003 May 31 - June 3; Chicago, IL. Abstract 901 in Proc Am Soc Clin Oncol, 2003 ASCO Annual Meeting Proceedings 2003;22.

38. Chu QS, Schwartz G, de Bono J, Smith DA, Koch KM, Versola MJ, et al. Phase I and pharmacokinetic study of lapatinib in combination with capecitabine in patients with advanced solid malignancies. J Clin Oncol 2007;25:3753-8.

39. Blackwell KL, Kaplan EH, Franco SX, Marcom PK, Maleski JE, Sorensen MJ, et al. A phase II, open-label, multicenter study of GW572016 in patients with trastuzumab-refractory metastatic breast cancer. ASCO, 40th Annual Meeting; 2004 June 5-8; New Orleans, LA. Abstract 3006 in J Clin Oncol, 2004 ASCO Annual Meeting Proceedings (Post-Meeting Edition) 2004;22(14S).

40. Burstein HJ, Storniolo AM, Franco S, Forster J, Stein S, Rubin S, et al. A phase II study of lapatinib monotherapy in chemotherapy- 
refractory HER2-positive and HER2-negative advanced or metastatic breast cancer. Ann Oncol 2008;19:1068-74.

41. Geyer CE, Forster J, Lindquist D, Chan S, Romieu CG, Pienkowski $\mathrm{T}$, et al. Lapatinib plus capecitabine for HER2-positive advanced breast cancer. N Engl J Med 2006;355:2733-43.

42. Clayton AJ, Danson S, Jolly S, Ryder WD, Burt PA, Stewart AL, et al. Incidence of cerebral metastases in patients treated with trastuzumab for metastatic breast cancer. Br J Cancer 2004;91:639-43.

43. Lin NU, Bellon JR, Winer EP. CNS metastases in breast cancer. J Clin Oncol 2004;22:3608-17.

44. Lin NU, Carey LA, Liu MC, Younger J, Come SE, Ewend M, et al. Phase II trial of lapatinib for brain metastases in patients with human epidermal growth factor receptor 2-positive breast cancer. J Clin Oncol 2008;26:1993-9.

45. Lin NU, Diéras V, Paul D, Lossignol D, Christodoulou C, Stemmler $\mathrm{HJ}$, et al. Multicenter phase II study of lapatinib in patients with brain metastases from HER2-positive breast cancer. Clin Cancer Res 2009;15:1452-9.

46. Blackwell KL, Burstein HJ, Storniolo AM, Rugo H, Sledge G, Koehler M, et al. Randomized study of Lapatinib alone or in combination with trastuzumab in women with ErbB2-positive, trastuzumab-refractory metastatic breast cancer. J Clin Oncol 2010;28:1124-30.

47. Boussen H, Cristofanilli M, Zaks T, DeSilvio M, Salazar V, Spector N. Phase II study to evaluate the efficacy and safety of neoadjuvant lapatinib plus paclitaxel in patients with inflammatory breast cancer. J Clin Oncol 2010;28:3248-55.

48. Johnston S, Pippen J Jr, Pivot X, Lichinitser M, Sadeghi S, Dieras $\mathrm{V}$, et al. Lapatinib combined with letrozole versus letrozole and placebo as first-line therapy for postmenopausal hormone receptorpositive metastatic breast cancer. J Clin Oncol 2009;27:5538-46.

49. Schwartzberg LS, Franco SX, Florance A, O'Rourke L, Maltzman J, Johnston S. Lapatinib plus letrozole as first-line therapy for HER$2+$ hormone receptor-positive metastatic breast cancer. Oncologist 2010;15:122-9.

50. Guarneri V, Frassoldati A, Piacentini F, Jovic G, Giovannelli S, Oliva C, et al. Preoperative chemotherapy plus lapatinib or trastuzumab or both in HER2-positive operable breast cancer (CHERLOB Trial). Clin Breast Cancer 2008;8:192-4.

51. www.alttotrials.com.

52. Reddy N, Cohen R, Whitehead B, Koch KM, Stead A, Beelen AP, et al. A phase I, open-label, three-period, randomized crossover study to evaluate the effect of food on the pharmacokinetics of lapatinib in cancer patients. Clin Pharmacol Ther 2007;81:S16-7.

53. Ciccarese M, Lorusso V. How should we prescribe lapatinib to our patients: once daily or twice daily, and at what dose? J Clin Oncol 2009;27:314-5.

54. Koch KM, Reddy NJ, Cohen RB, Lewis NL, Whitehead B, Mackay $\mathrm{K}$, et al. Effects of food on the relative bioavailability of lapatinib in cancer patients. J Clin Oncol 2009;27:1191-6.

55. Lapatinib [package insert]. Research Triangle Park, NC: GlaxoSmithKline; 2007.

56. Migliaccio I, Gutierrez M, Wu M, Wong H, Pavlick A, Hilsenbeck $\mathrm{SG}$, et al. PI3 kinase activation and response to trastuzumab or lapatinib in HER-2 overexpressing locally advanced breast cancer (LABC). CTRC-AACR San Antonio Breast Cancer Symposium; 2008 December 10-14; San Antonio, TX. Abstract 34 in Cancer Res 2009;69 Suppl 2.

57. Avizienyte E, Ward RA, Garner AP. Comparison of the EGFR resistance mutation profiles generated by EGFR-targeted tyrosine kinase inhibitors and the impact of drug combinations. Biochem J 2008;415:197-206.

58. Eichhorn PJ, Gili M, Scaltriti M, Serra V, Guzman M, Nijkamp W, et al. Phosphatidylinositol 3-kinase hyperactivation results in lapatinib resistance that is reversed by the mTOR/phosphatidylinosito 3-kinase inhibitor NVP-BEZ235. Cancer Res 2008;68:9221-30.

59. Trowe T, Boukouvala S, Calkins K, Cutler RE Jr, Fong R, Funke R, et al. EXEL-7647 inhibits mutant forms of ErbB2 associated with lapatinib resistance and neoplastic transformation. Clin Cancer Res 2008; 14:2465-75.

60. Liu L, Greger J, Shi H, Liu Y, Greshock J, Annan R, et al. Novel mechanism of lapatinib resistance in HER2-positive breast tumor cells: activation of AXL. Cancer Res 2009;69:6871-8.

61. Di Nicolantonio F, Arena S, Tabernero J, Grosso S, Molinari F, Macarulla T, et al. Deregulation of the PI3K and KRAS signaling pathways in human cancer cells determines their response to everolimus. J Clin Invest 2010;120:2858-66.

62. Xia W, Bacus S, Husain I, Liu L, Zhao S, Liu Z, et al. Resistance to ErbB2 tyrosine kinase inhibitors in breast cancer is mediated by calcium-dependent activation of RelA. Mol Cancer Ther 2010;9:292-9.

63. Xia W, Bacus S, Hegde P, Husain I, Strum J, Liu L, et al. A model of acquired autoresistance to a potent ErbB2 tyrosine kinase inhibitor and a therapeutic strategy to prevent its onset in breast cancer. Proc Natl Acad Sci U S A 2006;103:7795-800.

64. Reis-Filho JS, Milanezi F, Carvalho S, Simpson PT, Steele D, Savage $\mathrm{K}$ et al. Metaplastic breast carcinomas exhibit EGFR, but not HER2, gene amplification and overexpression: immunohistochemical and chromogenic in situ hybridization analysis. Breast Cancer Res 2005;7:R1028-35.

65. Siziopikou KP, Ariga R, Proussaloglou KE, Gattuso P, Cobleigh $\mathrm{M}$. The challenging estrogen receptor-negative/ progesterone receptor-negative/HER-2-negative patient: a promising candidate for epidermal growth factor receptor-targeted therapy? Breast $\mathbf{J}$ 2006;12:360-2.

66. Siziopikou KP, Cobleigh M. The basal subtype of breast carcinomas may represent the group of breast tumors that could benefit from EGFR-targeted therapies. Breast 2007;16:104-7.

67. Al-Kuraya K, Schraml P, Torhorst J, Tapia C, Zaharieva B, Novotny $\mathrm{H}$ et al. Prognostic relevance of gene amplifications and coamplifications in breast cancer. Cancer Res 2004;64:8534-40.

68. Tan DS, Marchio C, Jones RL, Savage K, Smith IE, Dowsett M et al. Triple negative breast cancer: molecular profiling and prognostic impact in adjuvant anthracycline-treated patients. Breast Cancer Res Treat 2008;111:27-44.

69. Reis-Filho JS, Pinheiro C, Lambros MB, Milanezi F, Carvalho S, Savage K et al. EGFR amplification and lack of activating mutations in metaplastic breast carcinomas. J Pathol 2006;209:445-53.

70. Agrawal A, Gutteridge E, Gee JM, Nicholson RI, Robertson JF. Overview of tyrosine kinase inhibitors in clinical breast cancer. Endocr Relat Cancer 2005;12:S135-44.

71. Storniolo AM, Pegram MD, Overmoyer B, Silverman P, Peacock $\mathrm{NW}$, Jones SF, et al. Phase I dose escalation and pharmacokinetic study of lapatinib in combination with trastuzumab in patients with advanced ErbB2-positive breast cancer. J Clin Oncol 2008;26:331723.

72. Uberall I, Kolar Z, Trojanec R, Berkovcova J, Hajduch M. The status and role of ErbB receptors in human cancer. Exp Mol Pathol 2008;84(2):79-89.

73. Yamauchi H, Ueno NT. Targeted therapy in inflammatory breast cancer. Cancer 2010;116 Suppl 11:2758-9.

74. Harris AL, Nicholson S, Sainsbury JR, Farndon J, Wright C. Epidermal growth factor receptors in breast cancer: association with early relapse and death, poor response to hormones and interactions with neu. J Steroid Biochem 1989;34:123-31.

75. Osaki A, Toi M, Yamada H, Kawami H, Kuroi K, Toge T. Prognostic significance of co-expression of c-erbB-2 oncoprotein and epidermal growth factor receptor in breast cancer patients. Am J Surg 1992;164:323-6.

76. Harłozińska A, Bar JK, Wenderski R, Bebenek M. Relationship between c-erbB-2 oncoprotein, epidermal growth factor receptor, and estrogen receptor expression in patients with ductal breast carcinoma. Association with tumor phenotypes. In Vivo 1996;10:21722.

77. D'Alessio A, De Luca A, Maiello MR, Lamura L, Rachiglio AM, Napolitano M, et al. Effects of the combined blockade of EGFR and ErbB-2 on signal transduction and regulation of cell cycle regulatory proteins in breast cancer cells. Breast Cancer Res Treat 2010;123:387-96

78. DiGiovanna MP, Stern DF, Edgerton SM, Whalen SG, Moore D 2nd, Thor AD. Relationship of epidermal growth factor receptor expression to ErbB-2 signaling activity and prognosis in breast cancer patients. J Clin Oncol 2005;23:1152-60. 
79. Slamon DJ, Clark GM, Wong SG, Levin WJ, Ullrich A, McGuire WL. Human breast cancer: correlation of relapse and survival with amplification of the HER-2/neu oncogene. Science 1987;235:17782.

80. Järvinen TA, Liu ET. Simultaneous amplification of HER-2 (ERBB2) and topoisomerase IIalpha (TOP2A) genes-molecular basis for combination chemotherapy in cancer. Curr Cancer Drug Targets 2006;6:579-602.

81. Hajduch M, Jarosova M, Trojanec R, Indrak K, Spackova K, Papajik T, Cwiertka K. Cytogenetics and molecular biological markers in oncology and hematooncology. Klinická onkologie 2004;17(Supplementum):51-56.

82. Hajduch M, Palacova M, Trojanec R, Dusek L, Petrakova K, Spackova K et al. Anthracycline based chemotherapy decreases amplification status of Her-2/neu and topoisomerase II alpha genes in locally advanced breast cancer. J Clin Oncol, 2004 ASCO Annual Meeting Proceedings (Post-Meeting Edition). Vol 22, No 14S (July 15 Supplement), 2004:9521.

83. Hajduch M, Trojanec R, Bouchalova K, Kolar Z, Petrakova K, Cwiertka K, Svoboda M. Chromosome 17 polysomy and Her-2/neu status in metastatic breast cancer patients indicated to trastuzumab therapy. J Clin Oncol, 2005 ASCO Annual Meeting Proceedings. Vol 23, No. 16S, Part I of II (June 1 Supplement), 2005:9584.

84. Bouchalova K, Trojanec R, Kolar Z, Cwiertka K, Cernakova I, Mihal V et al. Analysis of ERBB2 and TOP2A gene status using fluorescence in situ hybridization versus immunohistochemistry in localized breast cancer. Neoplasma 2006;53,393-401.

85. Spector NL, Blackwell K, Hurley J, Hartus JL, Lombardi D, Bacus S, et al. EGF103009, a phase II trial of lapatinib monotherapy in patients with relapsed/refractory inflammatory breast cancer (IBC): Clinical activity and biologic predictors of response. ASCO, 42th Annual Meeting; 2006 June 2-6; Atlanta, GA. Abstract 502 in J Clin Oncol, 2006 ASCO Annual Meeting Proceedings (PostMeeting Edition) 2006;24(18S)

86. Gomez HL, Chavez MA, Doval DC, Franco S, Arbushites M, Berger MS, et al. Investigation of tumor biomarkers as response predictors in a monotherapy study with lapatinib (L) as a first line treatment in ErbB2 amplified women with breast cancer. ASCO, 43th Annual Meeting; 2007 June 1-5; Chicago, IL. Abstract 10562 in J Clin Oncol, 2007 ASCO Annual Meeting Proceedings (PostMeeting Edition) 2007;25(18S).

87. Johnston S, Trudeau M, Kaufman B, Boussen H, Blackwell K, LoRusso P, et al. Phase II study of predictive biomarker profiles for response targeting human epidermal growth factor receptor 2 (HER-2) in advanced inflammatory breast cancer with lapatinib monotherapy. J Clin Oncol 2008;26:1066-72.

88. Finn RS, Press MF, Dering J, Arbushites M, Koehler M, Oliva C, et al. Estrogen receptor, progesterone receptor, human epidermal growth factor receptor 2 (HER2), and epidermal growth factor receptor expression and benefit from lapatinib in a randomized trial of paclitaxel with lapatinib or placebo as first-line treatment in HER2-negative or unknown metastatic breast cancer. J Clin Oncol 2009;27:3908-15.

89. Blackwell KL, Pegram MD, Tan-Chiu E, Schwartzberg LS, Arbushites MC, Maltzman JD, et al. Single-agent lapatinib for HER2-overexpressing advanced or metastatic breast cancer that progressed on first- or second-line trastuzumab-containing regimens. Ann Oncol 2009;20:1026-31.

90. Blackwell KL, Burstein H, Pegram M, Storniolo AM, Salazar VM, Maleski JE, et al . Determining relevant biomarkers from tissue and serum that may predict response to single agent lapatinib in trastuzumab refractory metastatic breast cancer. ASCO, 42th Annual Meeting; 2005 May 13-17; Orlando, FL. Abstract 3004 in Proc Am Soc Clin Oncol, 2005 ASCO Annual Meeting Proceedings $2005 ; 23$.

91. Isakoff SJ, Engelman JA, Irie HY, Luo J, Brachmann SM, Pearline $\mathrm{RV}$, et al. Breast cancer-associated PIK3CA mutations are oncogenic in mammary epithelial cells. Cancer Res 2005;65:10992-1000.

92. Toi M, Iwata H, Fujiwara Y, Ito Y, Nakamura S, Tokuda Y, et al. Lapatinib monotherapy in patients with relapsed, advanced, or metastatic breast cancer: efficacy, safety, and biomarker results from Japanese patients phase II studies. Br J Cancer 2009;101:1676-82.
93. Atkins MB, Yasothan U, Kirkpatrick P. Everolimus. Nat Rev Drug Discov 2009;8:535-6.

94. Li J, Yen C, Liaw D, Podsypanina K, Bose S, Wang SI, et al. PTEN, a putative protein tyrosine phosphatase gene mutated in human brain, breast, and prostate cancer. Science 1997;275:1943-7.

95. Knobbe CB, Lapin V, Suzuki A, Mak TW. The roles of PTEN in development, physiology and tumorigenesis in mouse models: a tissue-by-tissue survey. Oncogene 2008;27:5398-415.

96. Xia W, Husain I, Liu L, Bacus S, Saini S, Spohn J, et al. Lapatinib antitumor activity is not dependent upon phosphatase and tensin homologue deleted on chromosome 10 in ErbB2-overexpressing breast cancers. Cancer Res 2007;67:1170-5.

97. Vivanco I, Rohle D, Versele M, Iwanami A, Kuga D, Oldrini B, et al. The phosphatase and tensin homolog regulates epidermal growth factor receptor (EGFR) inhibitor response by targeting EGFR for degradation. Proc Natl Acad Sci U S A 2010;107:645964.

98. Mendes-Pereira AM, Martin SA, Brough R, McCarthy A, Taylor JR, Kim JS, et al. Synthetic lethal targeting of PTEN mutant cells with PARP inhibitors. EMBO Mol Med 2009;1:315-22.

99. Rouleau M, Patel A, Hendzel MJ, Kaufmann SH, Poirier GG. PARP inhibition: PARP1 and beyond. Nat Rev Cancer 2010;10:293-301.

100. Picard S, Titier K, Etienne G, Teilhet E, Ducint D, Bernard MA, et al. Trough imatinib plasma levels are associated with both cytogenetic and molecular responses to standard-dose imatinib in chronic myeloid leukemia. Blood 2007;109:3496-9.

101. Demetri GD, Wang Y, Wehrle E, Racine A, Nikolova Z, Blanke $C D$, et al. Imatinib plasma levels are correlated with clinical benefit in patients with unresectable/metastatic gastrointestinal stromal tumors. J Clin Oncol 2009;27:3141-7.

102. Faber E, Friedecký D, Micová K, Divoká M, Katrincsáková B, Rozmanová S, et al. Imatinib dose escalation in two patients with chronic myeloid leukemia, with low trough imatinib plasma levels measured at various intervals from the beginning of therapy and with suboptimal treatment response, leads to the achievement of higher plasma levels and major molecular response. Int J Hematol 2010;91:897-902.

103. Frame D. New strategies in controlling drug resistance. J Manag Care Pharm 2007;13:S13-7.

104. Faber E, Friedecky D, Tomkova J, Romanova S, Rohon P, Skoumalova I, et al. Imatinib plasma levels correlate with molecular response in CML patients. Haematologica 2008;93:S219.

105. Larson RA, Druker BJ, Guilhot F, O'Brien SG, Riviere GJ, Krahnke T, et al. Imatinib pharmacokinetics and its correlation with response and safety in chronic-phase chronic myeloid leukemia: a subanalysis of the IRIS study. Blood 2008;111:4022-8.

106. Bai F, Freeman BB 3rd, Fraga CH, Fouladi M, Stewart CF. Determination of lapatinib (GW572016) in human plasma by liquid chromatography electrospray tandem mass spectrometry (LC-ESI-MS/MS). J Chromatogr B Analyt Technol Biomed Life Sci 2006;831:169-75.

107. Haouala A, Zanolari B, Rochat B, Montemurro M, Zaman K, Duchosal MA, et al. Therapeutic Drug Monitoring of the new targeted anticancer agents imatinib, nilotinib, dasatinib, sunitinib, sorafenib and lapatinib by LC tandem mass spectrometry. J Chromatogr B Analyt Technol Biomed Life Sci 2009;877:1982-96.

108. Cizkova M, Bouchalova K, Friedecky D, Kolar Z, Hajduch M. Growth factor receptor 1 and 2 (HER1 and HER2) gene and protein assessment and evaluation of lapatinib plasma concentrations (PCS) in breast cancer patients. Proceedings of 21st International Congress on Anti-Cancer Treatment 2010 1-5 January; Paris, FR; 2010. p. 211.

109. Mičová K, Friedecký D, Faber E, Polýnková A, Adam T. Flow injection analysis vs. ultra high performance liquid chromatography coupled with tandem mass spectrometry for determination of imatinib in human plasma. Clin Chim Acta. 2010 Aug 13. [Epub ahead of print]

110. Mičová K, Friedecký D, Polýnková A, Faber E, Adam T. Determination of tyrosine kinase inhibitors in human plasma by UHPLC-MS/MS. Chem Listy 2010;104:31-34. 